Revista de Psicología de la PUCP. Vol. XIX, 1, 2001

\title{
Representaciones acerca del cáncer y su origen en padres de niños diagnosticados con esta enfermedad ${ }^{1}$
}

\author{
María Lourdes Ruda Santolaria ${ }^{2}$ \\ Pontificia Universidad Católica del Perú
}

En este estudio exploratorio se pretende precisar el modo como un grupo de progenitores de niños diagnosticados con cáncer se representan esta enfermedad y su etiología. Para ello, se entrevistó a 63 padres de 50 niños que iniciaban su tratamiento. A nivel cualitativo, se realizó un análisis de contenido que permitió la definición de categorías representacionales. Con el registro de frecuencias de estas últimas, se llevó a cabo un análisis estadístico de componentes principales que informó de la presencia de doce grupos representacionales. Los resultados nos muestran que si bien de manera explícita predomina la representación del cáncer como una enfermedad curable si es diagnosticada a tiempo y recibe tratamiento, a la base persiste la vinculación de los procesos oncológicos con la muerte. Las diferencias encontradas en las representaciones de los padres y madres de un mismo niño acerca de este padecimiento revelan, además, la importancia del elemento personal en la formación de las mismas. Las variables socio-económicas y culturales y la presencia de antecedentes familiares de neoplasias malignas son las que marcan mayores diferencias en la intensidad con que se presentan los grupos representacionales.

Palabras clave: representaciones, cáncer, padres, niños.

\section{Mentally representations about cancer and its etiology of parents of children diagnosed with cancer}

The following is an exploratory study that intends to precise the way in which a group of parents of children diagnosed with cancer mentally represent this disease and its etiology. For this, 63 parents of 50 children who were beginning their treatment were interviewed. At a qualitative level, a content analysis was carried out which allowed the definition of representational categories. With the frequency registration of the latest, a statistical analysis of the main components was carried out which informed of the presence of twelve representational groups. The results show us that although explicitly there predominates the representation of cancer as a curable disease if it is diagnosed soon enough and it receives treatment, deep down persists the link of oncological processes with death. The differences found in the representations of fathers and mothers of a specific child about this disease also reveal the importance of the personal element in the formation of them. The social-economical and cultural variables and, the presence of family antecedents of malignant neoplasm, are the ones which mark the greater differences in the intensity with which these representational groups appear.

Keywords: Representations, cancer, parents, children.

1. Se agradece a la Mg. Isabel Niño de Guzmán, asesora de tesis y a la Lic. María Liliana Montalbetti por sus valiosos aportes como supervisora del trabajo desde el Instituto de Enfermedades Neoplásicas.

2. Licenciada en Psicología, especialidad Clínica, de la PUCP. Realizó su residencia en PsicoOncología (Instituto de Enfermedades Neoplásicas). Es psicoterapeuta con orientación psicoanalítica y profesora de la Especialidad de Psicología de la PUCP. 

El paso del estado de salud a un estado de enfermedad supone en el individuo una experiencia de frustración y dolor que puede llevar, a la par, la desorganización de sus estructuras psíquicas y la ruptura de sus vínculos objetales. Precisamente, por ello exige una reorganización que lo lleve a configurar una nueva identidad. Todo esto se hace especialmente patente en el caso de las enfermedades crónicas y en los estados terminales en los que el enfermar deviene de condición de estado a esencia (Gala, Costa, Díaz y Lupiani, 1994).

El cáncer, en tanto se encuentra ligado a lo misterioso, lo desconocido e incontrolable, moviliza, en las personas que lo padecen como en la población general, montos elevados de angustia vinculados, entre otras cosas, a la posibilidad de desintegración. En ese sentido, la persona que experimenta esta enfermedad buscará construir, a nivel interior, un registro representacional que le permita organizar su vida psíquica, sus sentimientos y la interrelación que mantiene con su propio cuerpo.

La representación puede ser definida, de manera general, como un proceso activo a través del cual la persona intenta descubrir, ordenar e interpretar el mundo que le rodea, trasladando los eventos externos a modelos internos con, a su vez, un efecto en su conducta.

Desde la psicología social, se recurre al concepto de representación social para referirse a aquello que "concierne a la manera cómo nosotros, sujetos sociales, aprehendemos los acontecimientos de la vida diaria, las características de nuestro medio ambiente, las informaciones que en él circulan, a las personas de nuestro entorno próximo o lejano" (Jodelet, 1988, p. 473).

Si bien es un conocimiento práctico, socialmente elaborado y compartido - al que habitualmente se denomina sentido común y que es adquirido de manera espontánea a partir de la experiencia propia 
y de las informaciones, conocimientos y modelos de pensamiento que recibimos-, no se trata de un puro reflejo del mundo exterior, pues trae consigo elementos de autonomía y creación individual y colectiva.

La imposibilidad de acceder a la realidad externa como tal es una premisa también reconocida por los constructivistas, quienes consideran que nuestra comprensión de la realidad es necesariamente limitada, aunque se genere un fenómeno ilusorio por el cual creemos que percibimos el mundo directamente y no la representación de él (Johnson-Laird, 1985; Neimeyer y Neimeyer, 1996)

El concepto de modelo mental -que surge dentro de este marco conceptual - ayuda a entender cómo las estructuras de significado que contienen el conocimiento de una persona y que son usados por esta para entender el mundo y teorizar acerca de él suelen activarse cuando hay que resolver un problema particular: proveen de un espacio de trabajo para la inferencia y las operaciones mentales que pueden, luego, ser trasladadas a acciones. Ellas pueden ser transferidas de una situación hacia otra y recuperadas de la memoria cuando una representación particular se asocia con una situación del pasado (Johnson-Laird, 1985; Craig, 1992; Lakoff, 1987; Hallford, 1993).

Las representaciones, de otro lado, necesitarán del lenguaje para ser expresadas pues, precisamente, las descripciones verbales que uno realiza del mundo son las que nos permiten experimentarlo como próximo (Johnson-Laird, 1985).

Desde una perspectiva psicoanalítica, en este sentido conceptualiza la representación como aquello que del objeto viene a inscribirse en los sistemas mnémicos mediante el uso de la palabra (Laplanche y Pontalis, 1993); pues desde Freud, ellos distinguen dos tipos de representaciones a saber: las representaciones-cosa y las representaciones-palabra. 
Representaciones aceca del cáncer y su origen en padre de niños diagnosticados...

Las representaciones-cosa son producidas por registros de todos los sentidos y pertenecen al inconsciente; ellas requieren de las representaciones-palabra, para acceder a la conciencia. Por otro lado, estas últimas son pues el representante ante la conciencia de las primeras, en tanto significante de ella.

Las representaciones-palabra, fundadoras del preconsciente con sede en el yo, son las que permiten pensar las relaciones lógicas entre las representaciones y llegar a nuevos razonamientos y niveles de complejidad. Nacen así todas las posibilidades que trae al ser humano la creación de la actividad de pensamiento, fruto de la creación del lenguaje, de las representaciones-palabra a él correspondientes (Valls, 1995).

Frente a una realidad como el diagnóstico de cáncer, es esperable que se pongan en marcha todos los procesos anteriormente descritos, tanto a nivel cognitivo como afectivo en aquellos implicados; en el caso de un niño enfermo, lo son fundamentalmente él mismo y sus padres. La persona realizará, pues, esfuerzos activos que le permitan, inicialmente, interpretar la situación con el fin de encontrar propósito y significado a estos acontecimientos para luego enfrentar o resolver el problema que se le plantea.

El interés por este tema surgió de la observación reiterada - a lo largo del tiempo de trabajo en el Instituto de Enfermedades Neoplásicas- de una suerte de tendencia o necesidad existente en las personas afectadas por esta enfermedad, o en su entorno próximo, de recurrir a imágenes o metáforas para referirse a la enfermedad, probablemente, en su intento de representar y comprender simbólicamente una realidad que como tal es difícil de materializar.

Estas operaciones tendrían una doble función para los progenitores, según lo señala Farr (1988): hacer que lo extraño resulte familiar y que lo invisible sea perceptible. De esta manera, se conseguiría que el cáncer, enfermedad desconocida e insólita, resulte menos amenazador 
luego de encontrar propósito y significado a la experiencia que, como lo expresan Neimeyer y Neimeyer (1996), intenta ser interpretada.

El origen de los procesos oncológicos será, así, otra fuente importante de estas representaciones, pues, tal como lo refiere Farr (1988), la búsqueda de causalidad es un aspecto lógico del pensamiento social, sobre todo cuando se trata de un objeto o acontecimiento nuevo acerca del cual no se tiene conocimiento y que, en este caso, estaría referido a los procesos oncológicos.

De acuerdo con la teoría de la atribución, encontraremos, pues, que es frecuente, en los casos en que la enfermedad esta acompañada de incertidumbre - como ocurre con las neoplasias malignas-, las personas busquen comprender las causas e implicancias de los acontecimientos que presencian y experimentan como un modo de ganar control sobre la situación (Nouvillas y Huici, 1990).

Pero, tal como lo manifiesta Perrichi (1986), "las ideas dominantes en relación con la enfermedad, particularmente en lo que respecta al origen y tratamiento de esta, son variadísimas. La abundancia de opiniones no se debe solamente a los conocimientos mayores de unos y a la ignorancia de otros [...], las ideas sobre la salud y la enfermedad están impregnadas a veces de subjetivismo [...]. Finalmente, cada uno se forma, más o menos conscientemente, su propia idea de la enfermedad y la salud" (p. 105).

Cuando el paciente es un niño, la frecuente afectación del narcisismo paterno se focaliza en torno a la cuestión de la etiología y de la herencia. Los padres elaboran, ciertas teorías etiológicas, a veces muy fantásticas, con el fin de negar toda carga hereditaria o, al contrario, asumir todo el peso de la transmisión de la "tara" por parte de uno de ellos (Ajuriaguerra y Marcelli, 1987). Los sentimientos de responsabilidad y culpa serán difíciles de manejar por los padres que llegan a concebir a la enfermedad como producto de la negligencia o una manifestación de un amor insuficiente (Perrichi, 1986). 
Representaciones aceca del cáncer y su origen en padre de niños diagnosticados...

Al no existir una certeza médica sobre algo, dirá Stern (1995), los padres se encontrarán colocados en una situación imposible en la que no pueden elaborar el significado de la estructura representacional del futuro. $Y$ al no poder imaginarse el futuro, no pueden evaluar el presente.

Por ello, la realidad tenderá a verse desde una perspectiva propia, a la quel se le adjudicará un significado personal especial que, a su vez, influirá en el comportamiento que aquella persona tenga hacia la situación de enfermedad, ya que la conducta ante la salud o enfermedad depende, en gran medida, de las interpretaciones que se hagan acerca de ella (Nouvillas y Huici, 1990).

Al respecto, Hallford (1993) remarca cómo las representaciones internas intervienen directamente en el proceso de control de acción. En este sentido, puede decirse que las representaciones que los padres de niños afectados por algún proceso oncológico construyen sobre dicha enfermedad cumplirán un rol de suma importancia, tanto en términos personales como en la relación que se establece con su hijo enfermo, pues, según Stern (1995) y Neimeyer y Neimeyer (1996), nuestra comprensión de la realidad siempre está inmersa y se forja interpersonalmente.

Para Stern (1995), las representaciones están fundamentalmente construidas sobre la base de la experiencia subjetiva de estar con otra persona; en tanto es así, los pequeños momentos de la rutina diaria que se presentan frecuentemente a nivel no verbal adquieren un peso fundamental; más aun cuando se trata de experiencias repetitivas que facilitan la formación de modelos o representaciones prototípicas que luego tienden a generalizarse.

Estas representaciones constituyen, más aun en el caso de los niños, una guía acerca de lo que se espera de ellos, cómo actuar, percibir, sentir e interpretar la relación con sus padres y las experiencias de vida. Una vez que estas se instauran, tienden a mantenerse estables e 
intentan continuar en vigencia por el mayor tiempo posible a pesar de que se introduzcan cambios en el modo en que sus padres actúan e interpretan los eventos (Stern, 1995).

Spitz (1986), Winicott (1957, 1965), Bion (1967) y, en general, los autores que trabajan el tema del vínculo madre-niño entienden la comunicación como una operación por medio de la cual una o varias personas llegan a influir sobre la percepción, los sentimientos, las emociones, el pensamiento o las acciones de una o varias personas de manera intencionada o no, como es el caso del bebé con su madre.

Estos aportes trasladados al contexto del departamento de pediatría de un hospital oncológico, estarían advirtiendo que la relación y por tanto la comunicación- que se establece entre un padre y su hijo enfermo -que, por su condición, suele encontrarse habitualmente regresionado- podrá facilitar o dificultar la reacción del niño respecto de sus emociones, su conducta y la comprensión que alcance de su situación.

Calman (1982) remarca al respecto el poder de la comunicación, tanto verbal como no verbal, pues observa que muchas veces los temores de familiares, amigos, enfermeras y doctores se convierten también en los miedos del paciente hasta el punto que puede llegar a afectar críticamente la aproximación que este último tiene hacia su enfermedad. Holland y Cullen (1986) también reconocen que las actitudes de la familia y amigos cercanos del paciente tienen un fuerte impacto sobre las representaciones que el mismo paciente desarrolla acerca de su padecimiento.

Se observa que la conducta del niño ante la enfermedad - de importancia notoria tanto para la evolución del proceso de curación como para el desarrollo personal del menor - está muy ligada a lo que el pequeño pueda percibir y absorber del conjunto de personas que le rodean a lo largo del tiempo que la padece (Loscertales, 1990). 
Representaciones aceca del cáncer y su origen en padre de niños diagnosticados...

Calman (1982) señala además la influencia de las creencias del propio paciente y de la sociedad acerca del cáncer, en la reacción y afrontamiento que tiene respecto de su situación. Es precisamente por ello que progresivamente quienes trabajan en este campo han ido prestando atención a este tema y resumiendo sus conclusiones que parten bien de la investigación, en algunos casos, o de sus observaciones en el trabajo clínico.

El estudio de los procesos de análisis de causas y consecuencias de la conducta y del estado de salud son de vital importancia para poder explicar, predecir y mejorar la conducta preventiva y terapéutica. Por tanto, es de suma importancia que el profesional de salud tenga en cuenta estos aspectos subjetivo -cogniciones, expectativas, opiniones y creencias acerca de los profesionales de salud, significado de los síntomas, medicación, cumplimiento, etc.-, pues de lo contrario, se puede perjudicar la satisfacción y cumplimiento terapéutico (Nouvillas y Huici, 1990) o puede conducir al médico a un fracaso en la comunicación con sus clientes aún cuando él les proporcione información adecuada y detallada sobre su condición y enfermedad (Rebolloso, 1990).

En este sentido, a la luz de la propia experiencia de trabajo en el Instituto de Enfermedades Neoplásicas y de lo reportado anteriormente en términos de investigaciones previas o estudios teóricos, consideramos que el estudio de las representaciones de los progenitores respecto de las neoplasias malignas resulta relevante, no solo para comprender lo que ocurre internamente con los padres, sino por la influencia decisiva que ellas pueden tener tanto en el procesamiento y elaboración que cada uno de los progenitores y el propio niño puedan llevar a cabo de su padecimiento, como en el afrontamiento que hagan de la enfermedad. Los resultados que se obtengan, en este sentido, serán además de gran valor en la implementación del trabajo terapéutico con la población afectada pues podrá ofrecer luces para hacer más fructífera la tarea. 
A partir de lo anterior, se nos plantea, entonces, el problema de conocer cuáles son las representaciones que surgen sobre el cáncer y su origen en un grupo de padres de niños diagnosticados con esta enfermedad.

\section{Objetivos de la investigación}

El presente estudio tiene como objetivo general explorar las representaciones que un grupo de padres de niños con cáncer tienen sobre esta enfermedad y sus causas.

En términos específicos, nos planteamos los siguientes objetivos:

1. Explorar si las categorías representacionales de los padres sobre el cáncer se agrupan de modo tal que determinan la formación de grupos o esquemas representacionales.

2. Explorar si existen representaciones acerca del cáncer y su origen en función de las siguientes variables controladas:

- en relación con los padres: sexo, edad, estado civil, grado de instrucción, lugar de procedencia.

- en relación con el niño enfermo: sexo y edad.

- en relación con la familia: antecedentes de cáncer, número de hijos, nivel socio-económico, uso de tratamientos folklóricos.

- en relación con la enfermedad del niño: tiempo de enfermedad, diagnóstico y sintomatología con que se presenta.

\section{Metodología}

Se trata de un estudio exploratorio con un diseño pre-experimental de tipo " $\mathrm{x}-\mathrm{o}$ " de una sola medición (Kerlinger, 1988; Hernández, Fernández y Baptista, 1991). Se investigan las representaciones sobre el cáncer en una única población y se intenta identificar variables y sus relaciones. 
Los resultados incluyen tanto elementos cuantitativos como cualitativos, pero se pone énfasis en estos últimos con el fin de poder profundizar en la información obtenida. El análisis que se realiza es de tipo inductivo (Patton Quinn, 1990).

\section{Participantes}

Se empleó un muestreo de tipo no probabilístico accidental pues la elección de los sujetos dependió de la disponibilidad de los entrevistados (Hernández, Fernández y Baptista, 1991).

$\mathrm{Al}$ seleccionar la muestra, se consideró que el paciente no tuviera más de un mes de contacto con la institución y que se encontrara en la primera semana de su primera hospitalización. El niño debía tener entre 0 y 12 años y estar acompañado, por lo menos, por uno de sus padres durante su internamiento.

La muestra estuvo constituida por 63 padres de 50 niños enfermos de cáncer. Solo en el caso de trece niños (26\%) se entrevistó a ambos progenitores; en treinta y dos $(64 \%)$ se contó con la participación exclusiva de la madre y en cinco casos $(10 \%)$, el padre asistió solo a la evaluación.

En este sentido, se contó con dieciocho padres $(28,6 \%)$ y cuarenta y cinco madres $(71,4 \%)$. La edad del grupo oscilaba entre 19 y 50 años, siendo la edad promedio 35 años. En relación con el lugar de procedencia, se distingue una clara mayoría de los padres que provienen de la sierra (34) mientras que un mínimo de ellos tienen origen amazónico (3). La muestra es predominantemente católica (59).

Respecto del nivel de instrucción, más de la mitad de los entrevistados no ha concluido con los estudios secundarios. La tercera parte (20) de la muestra es analfabeta o con estudios incompletos de primaria. Los que cuenta con un nivel superior de instrucción (técnico o universitario) fueron doce (Cuadro 1). 


\section{Cuadro 1}

Descripción de la muestra según grado de instrucción de los padres

\begin{tabular}{|lll|}
\hline Grado de Instrucción & $f$ & $\%$ \\
\hline Analfabeto - primaria incompleta & 20 & 31.7 \\
Primaria completa - secundaria incompleta & 15 & 23.8 \\
Secundaria completa & 16 & 25.4 \\
Superior técnica/universitaria & 12 & 19.0 \\
\hline Total & 63 & 100.0 \\
\hline
\end{tabular}

La mayoría de las madres (29) se dedica al cuidado del hogar y de sus hijos. El resto de ellas se distribuye homogéneamente entre las diversas ocupaciones, ya sea como profesional o técnica, como independiente o empleada. Los padres (18) en su mayoría (9) laboran como empleados, solo cinco realizan actividades independientes y cuatro ejercen una profesión.

El nivel socioeconómico de las familias - según los criterios del Departamento de Servicio Social del Instituto de Enfermedades Neoplásicas-, alrededor de la mitad, corresponden a un nivel mediobajo (semi-indigente) y el resto se distribuye entre los niveles bajo (indigentes) y medio (semi-pagante/asegurado) con cierta preponderancia del grupo menos favorecido económicamente (Cuadro 2).

\section{Cuadro 2}

Descripción de la muestra según el nivel socio-económico

\begin{tabular}{|lcc|}
\hline Nivel Socio-económico & $f$ & $\%$ \\
\hline Indigente & 17 & 27.0 \\
Semi-indigente & 33 & 52.4 \\
Semi-pagante/asegurado & 13 & 20.6 \\
\hline Total & 63 & 100.0 \\
\hline
\end{tabular}

Los entrevistados son padres de 50 niños - treinta y seis hombres y veintisiete mujeres - con una edad promedio de 6,7 años (ran- 
Representaciones aceca del cáncer y su origen en padre de niños diagnosticados...

go de edad: 0 a 12 años). Estos niños presentaron los primeros síntomas hace menos de un mes en más de la mitad de los casos; sin embargo, en el grupo se observa gran dispersión respecto del tiempo de enfermedad pues este fluctúa entre los quince días y más de un año.

El Cuadro 3 resume la información relacionada con el diagnóstico de los niños.

\section{Cuadro 3}

Descripción de la muestra según diagnóstico del niño

\begin{tabular}{|lcc|}
\hline Diagnóstico del niño & $f$ & $\%$ \\
\hline Leucemia & 24 & 48 \\
Linfoma & 7 & 14 \\
Tumor sólido & 19 & 38 \\
\hline Total & 50 & 100 \\
\hline
\end{tabular}

Tal como puede observarse, de los menores, veinticuatro sufren de leucemia, siete son diagnosticados de linfoma y diecinueve presentan algún tipo de tumoración cancerígena (sólidos). Ello guarda proporciones similares con las estadísticas del Instituto de Enfermedades Neoplásicas (1994) correspondientes al período 1990-1992: de los 894 niños diagnosticados (0-14 años), un 57\% corresponde a leucemias y linfomas mientras que el $43 \%$ presenta tumores sólidos.

En treinta casos, los padres tienen algún familiar que está pasando o ha pasado por esta enfermedad que contrasta con los treinta y tres restantes que no han vivido esta experiencia. Por otro lado, 53 progenitores informan haber recurrido en alguna ocasión a la medicina tradicional mientras que diez solo ha recurrido a tratamientos meramente científicos. 


\section{Instrumentos}

- Ficha de datos demográficos. Se consignó información sobre las variables referidas al padre, el niño, la familia y la enfermedad.

- Entrevista individual semiestructurada (Kerlinger, 1988). Fue elaborada para explorar dos temas básicos: el modo cómo el cáncer era conceptualizado por el padre y las causas que, a entender del mismo, eran las responsables de esta enfermedad. Antes de iniciar la entrevista se remarcó que las preguntas no estaban referidas al diagnóstico de sus hijos, sino a las neoplasias malignas en general.

Las preguntas de la entrevista fueron elaboradas tomando en consideración las sugerencias de una serie de expertos en el trabajo con estos pacientes. El listado temático consistió en lo siguiente:

- ¿Qué considera usted que es el cáncer?; ¿cómo se lo imagina?; ¿qué efectos produce dentro del cuerpo?; ¿cómo es en términos físicos?

- ¿De dónde cree usted que viene el cáncer?; ¿por qué se origina?

Las entrevistas fueron consignadas textualmente por escrito mientras se realizaban y posteriormente organizadas en categorías de acuerdo con los temas (Patton Quinn, 1990).

De este modo, se elaboró una plantilla de corrección que organizó todo el material recolectado y que, a la base, tomó en consideración aspectos teóricos que la sustentaran. Se establecieron múltiples categorías que fueron definidas operacionalmente y que los jueces se encargaron de evaluar en términos de su adecuación y pertinencia para luego calificar el material de acuerdo con ella. 
Representaciones aceca del cáncer y su origen en padre de niños diagnosticados...

\section{Procedimiento}

Todos los padres de los niños que ingresaban al Departamento de Pediatría en el Instituto de Enfermedades Neoplásicas fueron citados al Servicio de Psicología; a ellos se les explicó cuáles eran los objetivos la investigación y se les solicitó su consentimiento para formar parte de la misma. Se procedió entonces a consignar los datos de la ficha demográfica y posteriormente se inició la entrevista (en los casos en que concurrieron ambos padres del niño, se entrevistó a cada uno de ellos individualmente). Posteriormente, se les ofreció una sesión de apoyo y se les comunicó que tanto ellos como su hijo serían atendidos por el Servicio a lo largo de todo el internamiento del menor.

Las entrevistas fueron transcritas textualmente. Posteriormente se elaboró una plantilla de corrección tentativa que permitió organizar, de manera sistemática, todo el material recolectado. Se determinaron así temas y categorías representacionales al interior de ella que fueron definidos operacionalmente.

De este modo, tal como señalan Banister, Burman, Parker, Taylor y Tindall, (1994), el análisis temático constituyó una forma coherente de organizar el material bajo títulos, haciendo justicia tanto con los elementos de la investigación como con las preocupaciones del entrevistado respecto de los distintos tópicos.

Para asegurar la validez del instrumento, se revisó la plantilla de corrección en dos ocasiones. En un primer momento, se entregó a cinco jueces la plantilla tentativa junto con doce entrevistas seleccionadas al azar. A estos se les solicitó que juzgaran la pertinencia de la misma y señalaran si consideraban que la plantilla permitía recoger los contenidos expresados por los padres. Sobre la base de las recomendaciones de los jueces, se reestructuró la plantilla. En un segundo momento, esta plantilla revisada fue entregada a tres nuevos jueces junto con la totalidad de las entrevistas; ellos determinaron la adecuación de las categorías representacionales planteadas. 
Posteriormente, para asegurar la confiabilidad entre calificadores, se solicitó a estos tres últimos jueces que revisaron totalidad de las entrevistas; se tomó en cuenta como calificación adecuada aquellas en las que por lo menos dos de los tres jueces mostraron acuerdo. Por último, se realizaron los análisis estadísticos que se describen en los resultados.

\section{Resultados}

A partir de la entrevista con los padres, se realizó, tal como ya se ha señalado, un análisis de contenido, para lo cual se elaboró una plantilla de corrección que permitiera organizar el material de manera más sistemática bajo títulos que constituyeron categorías representacionales definidas operacionalmente y que, a su vez, fueron agrupadas en dos temas básicos: el primero de ellos referido al concepto de cáncer y el segundo, a las causas de esta enfermedad.

El siguiente Cuadro detalla estas categorías representacionales consignando en cada caso su frecuencia y porcentajes de aparición en la muestra -independientemente del número de veces que hubiera sido mencionada por cada padre.

\section{Cuadro 4}

Categorias representacionales

\begin{tabular}{|lrrr|}
\hline Representaciones & $f$ & $\%$ & Error Estándar \\
\hline Tema I: Concepto de cáncer & & & \\
Muerte y expectativa de vida & 1 & 2 & 0.02 \\
Curable & 27 & 43 & $0.06^{*}$ \\
Curable con tratamiento & 7 & 11 & $0.04^{*}$ \\
Cura vinculado a lo mágico & 7 & 13 & $0.04^{*}$ \\
Contradicción respecto a la cura & 9 & 14 & $0.04^{*}$ \\
Cronicidad & 11 & 17 & $0.05^{*}$ \\
Incurable / mata & 9 & 14 & $0.04^{*}$ \\
Maligno & 11 & 17 & $0.05^{*}$ \\
Benigno-maligno con avance y/o tratamiento & & & \\
\hline
\end{tabular}


Representaciones aceca del cáncer y su origen en padre de niños diagnosticados...

Cuadro 4 (continuación)

\begin{tabular}{|c|c|c|c|}
\hline Representaciones & $f$ & $\%$ & Error Estándar \\
\hline \multicolumn{4}{|l|}{$\begin{array}{l}\text { Imágenes del cáncer traducidas en } \\
\text { términos corporales }\end{array}$} \\
\hline Tumor / bolita & 37 & 59 & $0.06 *$ \\
\hline Virus / microbio / infección & 29 & 46 & $0.06 *$ \\
\hline Gusano / bicho / animal & 10 & 16 & $0.05 *$ \\
\hline Células malas / extrañas & 10 & 16 & $0.05 *$ \\
\hline Herida interna / externa & 22 & 35 & $0.06^{*}$ \\
\hline \multicolumn{4}{|l|}{ Efectos físicos del cáncer en el cuerpo } \\
\hline Agresión al cuerpo: ataque directo & 16 & 25 & $0.06 *$ \\
\hline Agresión al cuerpo: cuerpo comido & 23 & 37 & $0.06 *$ \\
\hline Caos corporal & 4 & 6 & $0.03 *$ \\
\hline Posesión del cuerpo & 53 & 84 & $0.05 *$ \\
\hline Deterioro del cuerpo & 30 & 48 & $0.06 *$ \\
\hline Debilitamiento del cuerpo & 35 & 56 & $0.06 *$ \\
\hline Dolor físico & 33 & 52 & $0.06 *$ \\
\hline \multicolumn{4}{|c|}{ Efectos psíquicos del cáncer en la persona } \\
\hline Sentimiento de engaño & 33 & 52 & $0.06^{*}$ \\
\hline Miedo & 5 & 8 & $0.03 *$ \\
\hline Depresión & 12 & 19 & $0.05 *$ \\
\hline Angustia & 4 & 6 & $0.03 *$ \\
\hline Culpa & 1 & 2 & 0.02 \\
\hline $\begin{array}{l}\text { Connotaciones sociales y/o cultura } \\
\text { enfermedad } \\
\text { Tema II: Causas de la enfermedac } \\
\text { Causas }\end{array}$ & 5 & 8 & $0.03 *$ \\
\hline Enfermedades anteriores & 38 & 60 & $0.06^{*}$ \\
\hline Alimentación & 30 & 48 & $0.06 *$ \\
\hline Constitucional / congénito & 22 & 35 & $0.06 *$ \\
\hline Herencia & 18 & 29 & $0.06^{*}$ \\
\hline Sustancias & 18 & 29 & $0.06 *$ \\
\hline Falta de limpieza & 15 & 24 & $0.05^{*}$ \\
\hline Contagio & 14 & 22 & $0.05 *$ \\
\hline Contaminación & 13 & 21 & $0.05^{*}$ \\
\hline Emocional & 10 & 16 & $0.05 *$ \\
\hline Concepción & 8 & 13 & $0.04 *$ \\
\hline Sexual & 8 & 13 & $0.04 *$ \\
\hline Dios & 4 & 6 & $0.03 *$ \\
\hline
\end{tabular}

Nota. En este Cuadro solo se considerarán significativas las representaciones cuya proporción es superior a 1,96EE. $* p>1,96 \mathrm{EE}$. 
Sobre cada una de estas categorías representacionales se revisó con mayor profundidad los aspectos cualitativos que habían salido a la luz (Ruda, 1998). Posteriormente, se calculó el nivel de intensidad con la que cada categoría representacional se presentaba en cada uno de los participantes, para lo cual se registró el número de veces que un mismo sujeto se refería a aquella en distintos momentos de la entrevista. Se llevó a cabo entonces un análisis factorial por componentes principales - teniendo en cuenta el número y características de la muestra- con el propósito de determinar qué categorías representacionales eran afines o solían aparecer asociadas entre sí. De este modo, se conformaron doce grupos representacionales.

El Cuadro 5 resume los doce grupos representacionales y la intensidad con la que cada uno de ellos aparece en la muestra. Estos valores indican la proporción promedio en que las categorías representacionales que constituyen un grupo representacional que fueron mencionadas por un mismo sujeto.

\section{Cuadro 5}

Grupo de representaciones según la intensidad con que aparecen.

\begin{tabular}{|lc|}
\hline \multicolumn{1}{|c|}{ Grupo de representaciones } & Intensidad $(\mathrm{Me})$ \\
\hline Sexual & 0.20 \\
Mítico - religioso & 0.33 \\
Cronicidad & 0.20 \\
Caos corporal & 0.00 \\
Vínculo madre-niño & 0.33 \\
Consumo de sustancias & 0.75 \\
Daño corporal & 0.60 \\
Dolores físico y emocional & 0.20 \\
Hereditario & 0.20 \\
Herencia - maligno & 0.25 \\
Contradicción respecto a la cura & 0.33 \\
Ataque al cuerpo & 0.25 \\
\hline
\end{tabular}

Nota. $M e=$ mediana 
Luego de registrar la fuerza con la que cada grupo de representaciones se presentó en la muestra de trabajo, se pasó a describir el comportamiento de los grupos representacionales frente a las diversas variables demográficas.

Lo primero que nos interesa es determinar si las representaciones de los padres y madres de un mismo niño (13 casos) se encuentran relacionadas. Los resultados nos indican, al respecto, que existen diferencias significativas entre los grupos representacionales de uno y otro progenitor y, con ello, nos demuestran que las representaciones de los padres de un mismo niño no parecen asociarse entre sí, siendo más bien independientes. En este sentido, de aquí en adelante se trabajará con padres y madres, sin distinguir si son progenitores o no del mismo niño.

En relación con las variables demográficas referidas al padre, a la familia, al niño y a la enfermedad del mismo, se intentó determinar si cada una de ellas se asocia con los grupos representacionales conformados y de qué manera lo hacen en el caso de existir esta relación.

En el Cuadro 6 se consignan los grupos representacionales en los que las variables consideradas tienen alguna influencia en la intensidad con la que éstos se presentan. Se aplicaron para ello las pruebas no paramétricas —dado que la distribución de los puntajes no se ajustaba a las características de una distribución normal- UMann-Whitney y $\mathrm{H}$ de Kruskal-Wallis para dos o más grupos respectivamente; se trabajó con un nivel de significación de 0,05. Las agrupaciones en las que no se encuentran estas diferencias no han sido incluidas. 


\section{Cuadro 6}

Representaciones significativas de variables referidas al padre, a la familia, al niño y a su enfermedad

\begin{tabular}{|c|c|c|c|c|c|c|c|}
\hline Variables & $\begin{array}{l}\text { Grupo } 2 \\
\text { Mítico- } \\
\text { religioso }\end{array}$ & $\begin{array}{c}\text { Grupo } 3 \\
\text { Cronicidad }\end{array}$ & $\begin{array}{c}\text { Grupo } 4 \\
\text { Caos corporal }\end{array}$ & $\begin{array}{c}\text { Grupo } 8 \\
\text { Dolores físico } \\
\text { y emocional }\end{array}$ & $\begin{array}{c}\text { Grupo } 9 \\
\text { Hereditario }\end{array}$ & $\begin{array}{c}\text { Grupo } 11 \\
\text { Contradicción }\end{array}$ & $\begin{array}{c}\text { Grupo } 12 \\
\text { Ataque al } \\
\text { cuerpo }\end{array}$ \\
\hline \multicolumn{8}{|l|}{ Variables referidas al padre } \\
\hline Edad & - & - & - & - & - & $0.011 *$ & - \\
\hline Estado civil & - & - & - & $0.009 *$ & - & - & - \\
\hline Nivel de instrucción & - & - & $0.000^{*}$ & - & - & - & - \\
\hline Ocupación & - & - & $0.045^{*}$ & $0.024^{*}$ & - & - & - \\
\hline \multicolumn{8}{|l|}{ Variables referidas al niño } \\
\hline Edad & $0.045^{*}$ & - & - & - & - & - & - \\
\hline \multicolumn{8}{|c|}{ Variables referidas a la familia } \\
\hline Número de hermanos & - & $0.046^{*}$ & - & - & - & - & - \\
\hline Nivel socio-económico & - & - & $0.000^{*}$ & - & $0.006^{*}$ & - & $0.028 *$ \\
\hline Antecedentes de cáncer & $0.024^{*}$ & - & - & $0.041^{*}$ & - & - & - \\
\hline Tratamientos tradicionales & $0.031 *$ & - & $0.020^{*}$ & - & - & - & - \\
\hline \multicolumn{8}{|c|}{ Variables referidas a la enfermedad } \\
\hline Diagnóstico & - & 一 & - & 一 & - & - & $0.003^{*}$ \\
\hline Síntoma: tumoración & - & - & - & - & $=$ & - & $0.017 *$ \\
\hline
\end{tabular}

Nota. En este cuadro solo se incluyen las variables que arrojan un nivel de significación menor o igual a $.05 . \quad * p>.05$. 
Representaciones aceca del cáncer y su origen en padre de niños diagnosticados...

El Cuadro nos muestra que de las variables referidas al padre, la edad aparece vinculada a las representaciones que reflejan respecto de la cura, son los mayores quienes la mencionan con mayor intensidad.

De otro lado, vemos que el grupo de representaciones que prioriza en el cáncer los dolores físico y emocional se asocia tanto al estado civil como a la ocupación de los progenitores. Así, encontramos que son los solteros y las amas de casa quienes ponen mayor énfasis en esta idea.

El nivel de instrucción, por un lado, y la ocupación de los padres, por otro, generan diferencias en la magnitud con que son consideradas las representaciones ligadas al caos corporal; son aquellos que han alcanzado un nivel técnico/superior en su formación y quienes se dedican a actividades profesionales o técnicas los que ponen más fuerza en estas representaciones.

En el caso de las variables referidas al niño enfermo, se encuentra que la edad guarda relación con la intensidad con que se hace mención al grupo de representaciones con contenido mítico-religioso, disminuye cuando estamos frente a un infante menor de 4 años.

Las variables referidas a la familia marcan patrones de asociación importantes. Así, el número de hermanos se vincula a las representaciones que aluden a la cronicidad, de modo tal que los padres con 2 ó 3 hijos ponen un énfasis mayor en esta idea.

El nivel socioeconómico, por su parte, guarda relación con la fuerza de presentación de tres grupos representacionales, los ligados al caos corporal, a lo hereditario y aquel que alude al ataque al cuerpo. En los tres casos la intensidad es mayor cuando nos aproximamos al grupo con mejor situación económica en la muestra.

La presencia de antecedentes de cáncer en la familia se vincula con un mayor énfasis otorgado al grupo de representaciones mítico- 
religioso y a aquellas que denotan contenidos referidos a los dolores físico y emocional.

La fuerza con la que lo mítico-religioso se presenta es mayor cuando los participantes han recurrido en alguna ocasión a tratamientos tradicionales. Inversamente, el grupo de representaciones referidas al caos corporal se presentan es menor intensidad cuando en la familia ha considerado esta alternativa de tratamiento en dicha propuesta.

Las representaciones con contenidos de ataque al cuerpo se encuentran relacionadas con las variables de diagnóstico y tumoración como sintomatología de la enfermedad. Esta sería una idea especialmente intensa en los padres cuyos hijos padecen de leucemia y decrece en los padres que vieron debutar la enfermedad de sus hijos con una tumoración sólida.

\section{Discusión}

En relación con los resultados, el primer aspecto que llama nuestra atención se refiere a las proporciones en que se presentan las distintas categorías que aluden a la muerte y expectativas de vida. Al respecto, observamos que, si bien se habla de las neoplasias malignas como una enfermedad peligrosa, en tanto el riesgo de muerte se encuentra presente, se prefiere conservar una postura que mantiene en pie la esperanza en el tratamiento, en términos de expectativas y exigencias.

Así pues, encontramos que un $43 \%$ de la muestra considera que el cáncer es una enfermedad que puede ser curada, siempre y cuando sea diagnosticada a tiempo y la persona reciba tratamiento. $\mathrm{Y}$, dentro de esta misma línea, un $17 \%$ de los padres entrevistados asocia los elementos de benignidad o malignidad de la enfermedad al avance y a las posibilidades de curación. 
Representaciones aceca del cáncer y su origen en padre de niños diagnosticados...

En relación con este hallazgo, podríamos decir que esta posición tiene que ver con el hecho de que la población se hace cada vez más partícipe de los avances y progresos de la ciencia médica en lo que respecta a las neoplasias, eso suscita una aproximación más positiva hacia la enfermedad.

Sin embargo, desde otra perspectiva, y tomando en consideración el momento diagnóstico en que se encuentran los padres, podría elaborarse una hipótesis según la cual el shock que experimentan junto a los elevados niveles de angustia movilizados y a la sensación de vulnerabilidad generada los conduce a aferrarse a las posibilidades que se les ofrecen, en algunas ocasiones idealizándolas, pues ellos aún no han tenido el tiempo de adquirir confianza en el tratamiento por experiencia propia.

Es probable, pues, que bajo estas circunstancias surjan mecanismos de defensa que permitan, por así decirlo, la sobrevivencia emocional frente a una noticia que, por su impacto, amenaza la integridad psíquica de la persona, de modo que se le protege por un tiempo de ella hasta que logre reestructurarse e incorporar los nuevos acontecimientos.

Ello se evidencia de manera más clara en la contradicción en la que caen algunos padres al hablar de las posibilidades de curación de los procesos oncológicos. A nivel de grupos representacionales observamos al respecto que, cuanto más intensa es la contradicción que surge en relación con la posibilidad de cura, la representación del cáncer como una enfermedad curable con tratamiento se diluye. La escisión y la negación parecen presentarse, pues, como defensas que encubren o protegen contra la idea de muerte asociada a esta dolencia.

Algunos autores (López Merino, 1984; Rodríguez, López y Pastor, 1990) hablarán específicamente de la negación como un mecanismo de defensa típico de esta primera fase de la enfermedad que, sin embargo, es esperable que ceda gradualmente, en la medida que, si persiste hasta el final, bloquea la posibilidad de comunicación y de 
recibir ayuda. El método de la negación, dirá A. Freud (1993), se empleará en toda situación en que es imposible rehuir una impresión penosa procedente del mundo externo, como es la pérdida súbita de un objeto de amor o la amenaza de ella. En estas situaciones, el hecho real se niega y se sustituye algún aspecto de la realidad insoportable por una ilusión de algo deseado. No obstante, el yo no podrá usufructuar por mucho tiempo de este mecanismo, en tanto entra en contradicción con otra de sus funciones y más concretamente con la de examen de la realidad que impedirá la coexistencia de opuestos y hará que prevalezca la realidad sobre la fantasía.

En el caso de la escisión, el yo acepta la convivencia de dos ideas contradictorias dejando de lado temporalmente la función sintética que usualmente es prioritaria y que, probablemente, surgirá nuevamente como exigencia para estas personas luego de este momento inicial de enfrentamiento del diagnóstico de sus hijos.

Asimismo, vemos que la contradicción hacia la cura, como grupo representacional, se encuentra relacionado con la edad del padre. Así, se observa que son los mayores (40-50 años) los que otorgan más fuerza a estas ideas, en contraste con los de edades intermedias y menores. Esto quizá podría explicarse si se toma en consideración las posibilidades que cada cual considera que posee a futuro y las oportunidades que cree que tiene de rehacer su vida $o$, incluso, poder reafirmarse en su rol de padre con la opción de otro hijo, muy presente en la mente de ellos, aunque es evidente que no siempre esta intención de "reemplazo" de un niño con otro sea saludable.

Es probable, asimismo, que este hallazgo pueda estar dando cuenta de modificaciones en las representaciones acerca del cáncer, de las que no necesariamente puedan hacerse partícipes los padres de generaciones anteriores que asocian, con mayor fuerza, el cáncer a la muerte; por tanto, en ellos, la angustia que se desencadena es de tal magnitud que necesitan recurrir a los mecanismos a los que ya nos hemos referido. 
Representaciones aceca del cáncer y su origen en padre de niños diagnosticados...

La representación de los procesos oncológicos como crónicos viene adquiriendo, pues, cada vez más fuerza e implica la concepción de la enfermedad como presente a lo largo de toda la vida. No se habla de curación propiamente dicha, sino de la necesidad de una atención permanente. La percepción de que acorta el tiempo de vida, sin embargo, también está presente. Ello coincide con lo señalado por Rodríguez, López y Pastor (1990) quienes señalan que el cáncer tiene todas las características de una enfermedad crónica, en tanto puede ser definida por su curso prolongado y deterioro progresivo, marcado por el dolor, la hospitalización frecuente y la dependencia de los demás para las necesidades básicas.

En nuestro estudio, esto último también queda reflejado dado que el grupo de representaciones, centrado en esta idea, asocia la cronicidad a un debilitamiento físico gradual y al miedo que se experimenta frente a la posibilidad de sufrimiento.

Ahora bien, la intensidad con que aparecen dichas representaciones es mayor en aquellos padres cuyos hogares están constituidos por dos o tres niños, en contraste con los de familias más numerosas o que solo tienen un hijo. Esta vinculación podría ser explicada si se recurre a la noción de soporte social. Desde ella y, retomando nuestra propia experiencia de trabajo, podríamos decir que las familias más numerosas tienden, con frecuencia, a reorganizarse para cubrir, así, las obligaciones que la enfermedad conlleva tanto en términos económicos como del tratamiento en sí mismo; en ellas se reparten las nuevas funciones entre los distintos miembros del hogar, aunque sea por un tiempo prolongado. En cambio, en aquellas familias con pocos niños, las responsabilidades del hogar, la paternidad y ahora la enfermedad recaen sobre los padres y, por tanto, la idea de cronicidad que implica mantener este patrón de vida de manera constante cobra más fuerza porque supone una sobrecarga considerable en sus tareas.

Feldman (1974), por su parte, resalta la necesidad de poner en marcha respuestas de afrontamiento ante la enfermedad crónica que 
permitan la adaptación a dicha situación. La adaptación para él implicaría la reestructuración del entorno en el que la persona debe funcionar pero, sobre todo, supone una reorganización y aceptación del yo que conlleva el descarte tanto de falsas esperanzas como la desesperación destructiva y la posibilidad de encontrar propósito y significado para su vida trascendiendo las limitaciones impuestas por la enfermedad.

Hasta el momento, las representaciones que hemos venido analizando buscan, en mayor o menor medida, mantener en pie la esperanza en un tratamiento médico. En otros casos, sin embargo, si bien se conserva la idea de cura, la solución está puesta en métodos que salen completamente del control de la persona o de la ciencia, en tanto dependen de Dios o de la suerte. Estas representaciones dejan traslucir la impotencia que los padres experimentan frente a la situación que les toca vivir.

En contraste, la idea de muerte queda expresada tanto en la ausencia de representaciones de los procesos oncológicos como benignos, como en el reducido grupo de progenitores que confía en la cura de manera absoluta.

En la misma línea, la idea de malignidad respecto de las neoplasias y las representaciones que califican al cáncer como incurable aparece íntimamente vinculada a la muerte como consecuencia de la enfermedad. Las primeras añaden, sin embargo, un elemento adicional dado por la carga valorativa depositada en ellas, en tanto connotan "el bien y el mal" en lo que se refiere a los orígenes del cáncer y sus efectos en el cuerpo. En este aspecto, coincidiríamos con algunos autores (Schavelzon, 1978; Hersh, 1985; Sontag, 1996) que también observan que el cáncer es asociado, en muchas ocasiones, a una enfermedad sagrada en la que el sufrimiento encontraría explicación en las transgresiones conscientes o inconscientes que abordaremos con mayor profundidad más adelante. 
Representaciones aceca del cáncer y su origen en padre de niños diagnosticados...

En estos resultados encontramos puntos de coincidencia con estudios previos (Schmale, 1978; Hersh, 1979; Sontag, 1996) en lo que se refiere a la relación que existe entre cáncer y muerte. No obstante, nos alejamos de ellos, en alguna medida, al observar que si bien en muchas representaciones del cáncer subyace la idea de riesgo de muerte, esta en algunos casos de nuestra muestra se mantiene de manera encubierta debido a la angustia que supondría asumirla, ya que nos encontramos trabajando con padres que están afrontando el diagnóstico de sus hijos y, por lo tanto, que aceptan la muerte potencial de sus niños.

Al respecto, Freud (1915) planteará que, si bien todos estamos dispuestos a sostener que la muerte es el desenlace natural de la vida y que se trata de una cosa indiscutible e inevitable, en realidad, nos conducimos como si fuera de otro modo. Mostramos una patente inclinación a prescindir de ella y la eliminamos de la vida. La muerte propia es, desde luego, inimaginable y cuantas veces intentamos representarla, podemos observar que continuamos siendo en ello meros espectadores. Nuestro inconsciente dirá que no conoce en general ninguna negación $y$, por tanto, tampoco conoce la propia muerte a la que solo podemos dar un contenido negativo. En consecuencia, nada instintivo favorece en nosotros la creencia en la muerte.

Frente a esta posibilidad, indicará Bleger (1964) que la persona se desestructura dado que se queda sin futuro y, en esa medida, no puede organizar su presente de acuerdo con lo que se propone alcanzar.

En el caso de los padres, parte de su futuro está relacionado con su realización en el rol paterno porque ven a un hijo que crece y que, de acuerdo con el orden natural, continuará viviendo incluso después que él, como padre, fallezca (Nir y Maslin, 1980). La persona que al morir deja un hijo siente que a través de él trasciende a su propia muerte y permanece en alguna medida presente. Quizá este hecho hace que la situación resulte particularmente incomprensible y difícil de aceptar, más aun cuando se trata de un niño. 
Un segundo tema por abordar está constituido por las imágenes que se le otorgan al cáncer cuando se le intenta otorgar una textura material. Así, nos encontramos con que la representación que adquiere mayor fuerza es la de tumor; en estos casos, los padres se refieren a ella como una bola - bolita formada, para la mayoría de un coágulo de sangre- que surge a partir de un golpe en el que la sangre "no desfoga", no es liberada y por tanto se descompone ("mala sangre") orinando el tumor. A través de esta imagen y si trascendemos el terreno de lo físico, puede estarse aludiendo a las experiencias que golpean y no logran ser expresadas o canalizadas de manera apropiada y que son reprimidas y, por tanto, sus efecto se manifiestan posteriormente.

La representación del cáncer como una herida se presenta en la tercera parte de los padres entrevistados. Ellos hablan de una herida, granito o chupo, interno o externo, que no se cura, sino que se agranda y malogra hasta llegar al corazón, momento en que la persona fallece. Esta imagen traducida a nivel intrapsíquico recogería la imposibilidad de reponerse de una situación que marca con una herida y cuyo efecto va siendo progresivamente mayor y tomando diversas áreas de la persona.

Las representaciones del cáncer como un tumor y una herida mantienen, a la base, connotaciones similares en términos de la relación que la persona establece con su ambiente y cómo en este interjuego puede haber experiencias que producen una herida o golpean tan fuerte que la persona no logra sobreponerse.

Otras imágenes a las que una proporción significativa de los progenitores de nuestra muestra recurren es a la de virus, microbio, bacteria u hongo. En estos casos, se habla de un organismo unicelular, extraño al cuerpo, que entra a este y desarrolla en su interior su ciclo de vida a costa de aquel.

Esta misma idea se mantiene en las representaciones del cáncer como un bicho, gusano o cualquier otro tipo de animal. No obstante, 
Representaciones aceca del cáncer y su origen en padre de niños diagnosticados...

en estas últimas, los seres que habitan en el cuerpo son multicelulares y, por tanto, más desarrollados y diferenciados e, igualmente, más fuertes y agresivos.

En estas dos últimas representaciones se considera que la enfermedad viene de afuera y se introduce en el sujeto. El mal, de esta manera, se ubica en el exterior y el ambiente resulta amenazante; por lo tanto, es necesario protegerse de él.

Esto contrasta con las imágenes que nos ofrece otro grupo de padres quienes materializan el cáncer bajo la forma de células malas que surgen del mismo organismo al alterarse el ordenamiento interno que rige el funcionamiento del cuerpo. En estas representaciones, el mal surge del interior y se refiere al caos corporal que viene a simbolizar también el psíquico.

Las representaciones alusivas a los efectos físicos que el cáncer produce en el cuerpo sería el siguiente tema por discutir. Al respecto, llama la atención el uso de imágenes impactantes, en las que la enfermedad se visualiza como poderosa y agresiva, destructiva y devastadora, sin piedad. El cuerpo, por su parte, sufre dolores muy intensos pues es terriblemente dañado $\mathrm{y}$, por consiguiente, progresivamente debilitado. El control que anteriormente tenía el padre sobre el niño es cedido a este mal que invade y busca apoderarse del cuerpo del menor. El progenitor sentirá, entonces, que se le arrebata la autoridad y, por ello, se tornará frágil e inseguro.

Llama la atención, de manera especial, la proporción tan elevada de padres que mencionan representaciones que se refieren a la posesión del cuerpo, ligadas fundamentalmente a la sensación de falta de control de la enfermedad, de la situación, "del hijo" y al poco margen que se experimenta para luchar contra la dolencia. Sontag (1996) dirá, precisamente en esta misma línea, que para muchos el cáncer hace que células primitivas se multipliquen y crezcan de manera incontrolada hasta que sustituyen al yo por el no-yo. Para Hersh (1979), estas ideas 
asociadas al cáncer intentan dar cuenta de la percepción de una condición anormal del yo físico y simbolizan la realidad frágil de nuestro control más allá de nuestro apego a la vida.

El padre se siente, en este sentido, incapaz de proteger a su hijo de la invasión que ejecuta el cáncer en su interior y, frente a esto, experimenta impotencia. Quizá por ello, en muchos casos se observa que los progenitores, a lo largo del tratamiento, ceden su rol de autoridad a los médicos y personal del hospital, con quienes llegan a establecer una relación de dependencia. Ellos se sienten ineficientes y consideran que han fallado en el cumplimiento de su función paterna y temen volver a hacerlo pero, al mismo tiempo, compiten con aquel que intente interponerse entre él y su niño (Perrichi, 1986; Ajuriaguerra y Marcelli, 1987).

La representación del debilitamiento corporal, como consecuencia de las neoplasias malignas, aparece en más de la mitad de la muestra (56\%). La idea propuesta por Sontag (1996) de que el tumor es quien tiene la energía y no el paciente se repite aquí y alude, en términos del aparato psíquico, a un debilitamiento progresivo de las estructuras yoicas, si consideramos que las experiencias corporales juegan un rol de suma importancia en la constitución del yo como instancia psíquica (Schilder, 1977).

Esto, en el caso de niños enfermos, se observa también en los padres que, junto con los pequeños, empiezan a sentir la fatiga de la enfermedad y el tratamiento e, incluso, tal como lo señalan Montalbetti, Luy, Ruda y Cedrón (1996), llegan a identificarse en tal grado con sus hijos que pueden experimentar dolores similares y presentar junto con ellos algunos síntomas.

La representación del cáncer como asociado al dolor intenso, difícil de aliviar, surge en un grupo significativo de nuestros padres entrevistados $(52 \%)$ y es tomado tanto como un aviso de la enfermedad como de su avance. Si retomamos a Schilder (1977) diremos que la 
Representaciones aceca del cáncer y su origen en padre de niños diagnosticados...

estructura libidinal del modelo corporal se altera como producto del dolor que rompe con el equilibrio interno, de manera que se sobrecarga de libido narcisista la parte adolorida o el órgano enfermo que pasa a ser el centro de experimentación del cuerpo.

La idea del deterioro corpóreo como representación de los efectos del cáncer es mencionada por casi la mitad de los progenitores que participaron en este estudio (48\%). Se refiere a procesos de degeneración y putrefacción al interior de la persona.

La agresión de la enfermedad adquiere dos formas principales y, por tanto, surgen representaciones que corresponden a cada una de ellas. La primera se refiere al ataque directo $(25 \%)$ y coincide con lo señalado por Schmale (1978) y Sontag (1996). El cáncer viene a ser un enemigo diabólico en tanto entra como un bárbaro a arrasar con todo lo que encuentra a su paso. El tratamiento se ofrece entonces como arma de ataque y defensa para librar esta guerra con la enfermedad. El cuerpo se convierte en el escenario en donde se libera esta batalla, sufriendo los efectos devastadores de ambos bandos.

Estas representaciones, observadas desde una perspectiva psicodinámica, dan cuenta de elementos de agresión anal, en tanto expresan niveles de hostilidad elevados provenientes tanto de la enfermedad como del tratamiento en el intento de ambos de controlar y destruirse mutuamente.

Por otro lado, encontramos que la representación de ataque se contrapone a los hallazgos de Reátegui (1990). Él encuentra que en la mujer andina predomina la metáfora de convivencia con la enfermedad en la medida en que se cree en un equilibrio entre el mundo natural, sobrenatural y personal; ello supone que, en términos de tratamiento, se busque detener y sacar el mal antes que luchar contra él. Probablemente, esta creencia se diluye en nuestra muestra porque los padres que la conforman, si bien proceden de la sierra en su mayoría, se encuentran, en muchos casos, residiendo en Lima y pueden haber interiorizado patrones de pensamiento más occidentales. 
El segundo tipo de agresión al que aludíamos es más bien de tipo oral-canivalística, en términos de la propuesta de M. Klein (1971). En este caso, se habla de un cuerpo brutalmente devorado por el cáncer que se nutre y fortalece de él, a çosta de su destrucción. Schavelzon (1978), Goldberg (1981), Lockhart (1981), y Sontag (1996) también se refieren a ellos y remarcan la presencia de impulsos orales que salen fuera de control.

Este conjunto de representaciones permiten hablar, junto con Sontag (1996), de metáforas dantescas y apocalípticas en relación con los efectos físicos del cáncer en el cuerpo, de las que tanto al paciente como a sus familiares les resultará difícil desprenderse sin que ejerzan una influencia en la vivencia de la enfermedad, por una parte, y en el afrontamiento de la misma y de su tratamiento, por otra. Nos preguntamos, en este sentido, qué tipo de acercamiento puede tener un padre con su niño cuando considera que se están llevando a cabo en su interior procesos tan destructivos como los que estamos describiendo. De la misma manera, nos cuestionamos acerca del modo como los progenitores pueden llegar a integrar estas representaciones dentro de su esquema de pensamiento, considerando los significados que ellas conllevan.

Nuevamente, llama aquí nuestra atención el contraste que surge entre el matiz esperanzador que se ofrece al hablar del tratamiento y las expectativas de vida en relación con la enfermedad, por una parte, y estas imágenes tan caóticas, por otra, que, más bien, dan cuenta de la destrucción corporal por el mal. Esta contradicción nos hace pensar en que probablemente la idea de muerte continúa aún siendo estrechamente ligada al cáncer, aunque las personas que la viven de cerca prefieren negarla o aferrarse a las posibilidades que se les ofrecen en términos de tratamiento, pues, de lo contrario, no tendrían donde sostenerse.

Asimismo, si revisamos el modo en que se agrupan las representaciones referidas a los efectos físicos de los procesos oncológicos en 
Representaciones aceca del cáncer y su origen en padre de niños diagnosticados...

el cuerpo, obtendremos nuevos elementos de análisis. Así, vemos que en la mayoría de los casos se busca dar una textura material a la enfermedad y describir las consecuencias que produce.

El primer grupo de representaciones que surge al respecto es el referido al daño corporal: el cáncer es materializado como un animal que se come vorazmente el cuerpo y se fortalece de él, progresivamente lo invade y va tomando posesión de sus distintas partes y, en este sentido, produce un deterioro físico gradual de la persona.

Este grupo representacional aparece con una intensidad significativa y reúne quizá las imágenes más devastadoras dentro de las mencionadas, siendo estas comunes a la mayor parte de la muestra. Esto nos hace pensar que la situación de enfermedad remite a sentimientos muy primarios de amenaza, desprotección e impotencia experimentados frente a este mal que se apodera del cuerpo y lo aniquila sin que exista posibilidad de defensa. La persona queda ubicada, en este sentido, en un rol de espectador pasivo.

El grupo de representaciones ligadas al caos corporal, aunque es el que aparece con menor intensidad, es importante en tanto recoge la idea de desorden y falta de control y equilibrio al interior del cuerpo. La enfermedad toma la forma de células malas que podrían ser la causa o la consecuencia de tal desorganización, pero se les califica precisamente de "malas" en tanto salen de lo establecido y "no se comportan bien". En términos kleinianos, lo bueno y lo malo quedaría entonces escindido en el interior del cuerpo, como objetos parciales que no pueden ser integrados en un todo.

Quizá la particularidad de este grupo representacional, dentro del presente estudio, está en términos de presentar una correlación significativa entre algunas variables demográficas que se toman en consideración, tanto en relación con el padre (grado de instrucción y ocupación) como con la familia del niño enfermo (nivel socio-económico y uso de tratamientos tradicionales) y que, finalmente, aluden a aspectos socioeconómicos y culturales. 
Así, estas representaciones parecen adquirir mayor fuerza en aquellas personas que, al tener una mejor ubicación económica, pueden acceder a niveles de instrucción superiores y, en ese sentido, desempeñarse como profesionales o técnicos, apartándose, por otra parte, en alguna medida, de algunas costumbres como la medicina tradicional. En este sentido, se explica la baja intensidad con que se presenta este grupo representacional en la muestra, en tanto ella tiene un claro sesgo hacia niveles socio-económicos y educativos bajos.

Esta vinculación podría hacer pensar, entonces, que se trata de representaciones que requieren un mayor grado de simbolización que se acrecienta con la educación, el mismo que, a su vez, es fuente de información y conocimientos generales ligados a la ciencia.

Al respecto, ya Rodríguez, López y Pastor (1990) han resaltado la importancia de las variables sociodemográficas en la determinación de la forma en que el sujeto responde a la situación de enfermedad.

El grupo de representaciones que enfatiza la idea de ataque al cuerpo recurre a las imágenes de virus y herida como un modo de materializar los procesos oncológicos. La intensidad con que estas representaciones aparecen se vincula, nuevamente, al nivel socio-económico de la familia y aumenta en quienes poseen mayores recursos y disminuye progresivamente según estos van reduciéndose.

Por otra parte, el diagnóstico del niño y la presencia de una tumoración como parte de la sintomatología con la que se manifiesta la enfermedad también se asocian al énfasis que los padres ponen al referirse a estas representaciones. Así pues, se adjudica más fuerza a estas ideas cuando se trata de algún tipo de leucemia que cuando el diagnóstico corresponde a una tumoración sólida $-\mathrm{y}$ debuta con un bultito- ubicada en cualquier parte del cuerpo -incluidos los linfomas-. Vemos entonces la tendencia a materializar la leucemia como un virus o una herida, a diferencia de aquellas neoplasias en las que existe un tumor. 
Representaciones aceca del cáncer y su origen en padre de niños diagnosticados...

Otro de los grupos representacionales en que se pone de manifiesto la idea del cáncer como una enfermedad que agrede o ataca directamente al cuerpo es aquel referido a la conducta sexual de la persona como causa del cáncer. Esto será abordado con mayor profundidad más adelante.

La última de las agrupaciones que se constituye tomando en consideración los efectos físicos de las neoplasias malignas en el cuerpo es aquella en la que aparecen ligados los dolores físico y emocional específicamente depresión y angustia-; resulta especialmente significativa no tanto en términos de intensidad, como sí del paralelo que se establece entre las consecuencias de la enfermedad a nivel corporal y psicológico respecto del dolor que, desde ambos planos, se produce y la influencia de cada uno de ellos ejerce sobre el otro. Este grupo representacional reflejaría, por tanto, la experiencia integral y no diferenciada del dolor físico y afectivo. Esto coincide con los hallazgos de Rodríguez, López y Pastor (1990), quienes encuentran relación entre el dolor crónico y los estados emocionales anteriormente mencionados.

La Escuela Europea de Oncología (1997) registra que los trastornos de ansiedad y depresión son los más frecuentes en los pacientes que padecen de cáncer. Probablemente, dirán Rennecker (1980) y Sherman (1992), parte del potencial estresante del cáncer correspondería a la posibilidad de sufrimiento como producto de la sintomatología que se presenta gradualmente — según evoluciona la enfermedad - o de los tratamientos que se requieren. Desde un punto de vista teórico, la alta tasa de prevalencia de depresión entre los pacientes oncológicos puede reflejar las expectativas de desamparo engendradas o exacerbadas por el paciente con esa enfermedad dado que el cáncer es contemplado como una dolencia sobre la que no se puede tener control (Rodríguez, López y Pastor, 1990).

Asimismo, los resultados nos muestran, además, que la intensidad con que se presenta el grupo de representaciones ligado a los dolores físico y emocionales se encuentra asociado con el estado civil y 
la ocupación de los padres que conforman parte de nuestro estudio. Así, se observa que son las solteras y las amas de casa, respectivamente, quienes dan mayor énfasis a estas representaciones. En este sentido, podríamos hipotetizar que, en ambos casos, el vínculo con el niño y la maternidad constituyen funciones prioritarias para la realización personal de estas mujeres, lo cual incrementaría su preocupación en el bienestar físico y emocional de sus hijos y las centraría alrededor de ella. En cambio, el tener o haber tenido espacios personales y fuentes de realización alternativas - trabajo fuera del hogar y/o relación de pareja-reduce, en alguna medida, estas preocupaciones en la persona que, a su vez, encuentra fuentes adicionales de soporte.

Holland (1982), por su parte, señala que la capacidad del paciente para manejar el estrés generado por el diagnóstico de un proceso oncológico dependerá del nivel anterior de ajuste emocional, de la amenaza que la neoplasia signifique para el logro de las metas apropiadas a la edad, ocupación, familia, etc., de la presencia de personas que proporcionen apoyo emocional y de diversas variables determinadas por la enfermedad.

La presencia de antecedentes de cáncer en la familia es también una variable que marca incremento en la fuerza de estas ideas se presentan. Probablemente, ello responda, en parte, a lo reportado en algunos estudios respecto de la correlación existente entre el conocimiento que una persona tiene sobre una enfermedad y el poseer amigos y/o familiares que la padecen (Ley y Spelman, en Rebolloso, 1990). Para el caso de las neoplasias malignas, se aplicaría la misma lógica pero, quizá, no solo se trata de un conocimiento concreto, sino de la experiencia vivida a partir de la cual se concluye que se trata de una enfermedad dolorosa, tanto en términos físicos como emocionales.

Con respecto a esto último, nuestro estudio refleja algo de lo que Solidoro (1983) ya daba cuenta: la frecuencia con que surgen sentimientos de engaño, confusión y sorpresa en las personas que se encuentran afectadas por procesos oncológicos y, más aun, en el momento del 
Representaciones aceca del cáncer y su origen en padre de niños diagnosticados...

diagnóstico en que por primera vez tienen noticia de ello, generalmente, sin poder preverlo.

El cáncer es representado por más de la mitad de estos padres que acaban de ser "sorprendidos" por el diagnóstico de sus hijos, como una enfermedad que entra sin avisar, se oculta y se desarrolla silenciosamente para, finalmente, salir a la luz de manera brusca, de un momento a otro y sin posibilidad de acción por parte de ellos. Es explicable, en este sentido, el que este sentimiento prevalezca en este momento concreto sobre los demás y se acompañe además del temor de que la enfermedad continúe dando sorpresas.

La dolencia entonces será vivida con gran incertidumbre por la falta de control que se experimenta hacia ella y es precisamente a esto a lo que se refiere Koocher (1980) al hablar del Síndrome de Damocles como un componente importante de la capacidad estresante de este mal, en tanto pocas veces se puede realizar un pronóstico con alto grado de fiabilidad.

Ovejero (1990) añadirá que la incertidumbre de familiares y amigos puede incrementar las preocupaciones y temores, sobre todo cuando se trata de una enfermedad misteriosa o rara. Las atribuciones surgirán, entonces, en las personas como un intento de comprender las causas e implicancias de lo que ocurre, reduciendo la incertidumbre y aumentando la sensación de control sobre la situación.

En Lo Siniestro, Freud (1919) habla exactamente de esta mezcla de miedo y angustia frente a la muerte; el autor ubica en la incertidumbre de nuestro conocimiento científico y en nuestras reacciones afectivas primarias las condiciones básicas de este sentimiento.

Un aspecto que llama nuestra atención es la proporción en que surgen los sentimientos de culpa en los padres que forman parte de nuestra investigación, aunque estadísticamente no resulta significativa. Esto contrasta con los estudios previos (Lokich, 1978; Schavelzon, 
1978; Perrichi, 1986 y Ajuriaguerra y Marcelli, 1987) y con la observación de un elevado nivel de culpabilidad en los padres a largo de las dinámicas grupales que se llevaban a cabo con ellos en el transcurso del período de hospitalización y que, en cierta forma, impulsó el inicio de esta investigación. Al respecto, puede decirse que quizá la culpa es un sentimiento que tiende a ser expresado de manera indirecta y que aparece con mayor fuerza cuando los padres empiezan, luego del primer momento de diagnóstico, a buscar explicaciones a la enfermedad de sus hijos, cuando intentan determinar el origen de la misma o al ofrecer algunas connotaciones sociales y/o culturales claramente estigmatizantes de las neoplasias.

Estas últimas representaciones, que se presentan en un pequeño porcentaje de los padres, señalan que las neoplasias, al igual que otras enfermedades a lo largo de la historia, como la lepra, la tuberculosis, la peste bubónica y el SIDA, dan cuenta de la mano castigadora de Dios que intenta recuperar el orden y conciencia social a través del sufrimiento humano (Hersh, 1985; Chávez Ferre, 1995).

Sontag (1996) nos recuerda en esta línea que, para los antiguos, la enfermedad siempre fue un instrumento de la ira divina con el cual se enjuicia a la comunidad o a un individuo particular. En este sentido, se le adjudica un significado moralista: la enfermedad es la expresión de una enfermedad de la voluntad y, por tanto, la remisión de la misma dependería de la posibilidad de recuperar la voluntad.

El sentimiento de culpa se deja traslucir aquí con mayor claridad que lo que podíamos vislumbrarlo antes. Se apela a un Dios todopoderoso y castigador y, con ello, se deja constancia de la proyección en el afuera de una instancia crítica muy severa a nivel intrapsíquico. La presencia de Dios como parte de las representaciones estaría vinculada a una muestra eminentemente católica.

De este modo, vemos que al abordar el tema de las causas del cáncer, un grupo de los padres menciona que Dios es quien inventa y 
Representaciones aceca del cáncer y su origen en padre de niños diagnosticados...

envía esta enfermedad como una prueba o castigo, bien para el mismo paciente o para su familia. Ello también lo observamos en las reuniones de apoyo psicológico a padres, allí se encuentran verbalizaciones como "Dios castiga con lo que uno más quiere" que dan cuenta del sentimiento de responsabilidad que los progenitores tienen respecto de la enfermedad de sus hijos.

Bajo este contexto, la enfermedad es considerada como una experiencia que permite a las personas reflexionar acerca de sus actos y su vida en general para poder enmendarse, permitiendo así, en alguna medida, que la persona pase por una purga que lo limpia de sus errores. Al mismo tiempo, lo lleva a la toma de conciencia de la existencia de un ser todopoderoso que castiga cuando uno se equivoca y que con ello pretende que el sujeto rectifique sus actitudes, aunque simplemente sea por temor.

A nivel de grupo representacional, estos elementos mítico-religiosos aluden al caos social, al resquebrajamiento de los valores y la destrucción que el hombre hace de la naturaleza, asociándose a la depresión y/o sufrimiento moral.

La colocación de un énfasis mayor en estas representaciones es observada en aquellos padres que recurren a tratamientos tradicionales que, a su vez, tienen a la base elementos mágico-religiosos. De este modo, al vincular el origen de la enfermedad a un castigo de Dios implica que, para alcanzar la curación, sea necesario volver a conectarse con él a través de una serie de rituales a los que en múltiples ocasiones recurre la medicina folklórica. El elemento cultural juega aquí un papel importante.

De otro lado, se encuentra una mayor consideración de estas ideas en aquellos padres que presentan antecedentes de cáncer en sus familias, dando cuenta quizá, con ello, de un sentimiento de castigo recurrente hacia el grupo familiar. No obstante, pareciera que es difícil concebir que se escoja a los niños más pequeños como medio de 
castigo social o familiar pues este grupo representacional aparece con menor intensidad cuando el hijo enfermo se encuentra entre los $0 \mathrm{y}$ los 3 años.

Ahora bien, como antes decíamos, en este grupo representacional aparece la idea de un error no solo individual, sino de la humanidad como grupo social que, en ocasiones, va en contra de los valores o no cuida la naturaleza que se pone a su disposición. En este sentido, la contaminación ambiental es tomada en consideración como una acción humana irresponsable que podría ser la causa de las enfermedades neoplásicas. El énfasis está puesto aquí en el déficit en el cuidado de los espacios comunes por la comunidad.

Las represesentaciones que, por otro lado, ligan el cáncer a la falta de limpieza depositan la responsabilidad de la enfermedad, de manera casi directa, en aquellas personas encargadas de desempeñar esta función que, al tratarse de menores, recae en los padres. En términos simbólicos, puede hablarse de los déficits en la limpieza como falta de pureza. Esto podría interpretarse como el advenimiento de un sentimiento de estar en falta o "pecado", tanto de parte del niño como de sus padres.

Otras de las causas que se mencionan como agentes de los procesos oncológicos están dadas por los factores congénitos y la herencia. En ambos casos, los padres comparten un sentimiento de responsabilidad frente a este hijo que nace enfermo o con predisposición para desarrollar el mal.

La representación de las neoplásicas malignas como determinada por la herencia lleva al padre, en algunas ocasiones, a ubicar la responsabilidad de la enfermedad de su hijo en sí mismo y, en otras, a proyectarla sobre su pareja como un medio de reducir la culpa que pudiera sentir (Ajuriaguerra y Marcelli, 1987).

En nuestro estudio, ello se refleja en la constitución de dos grupos representacionales en donde la herencia implica la idea de la 
Representaciones aceca del cáncer y su origen en padre de niños diagnosticados...

transmisión de una dolencia al interior de la familia, de una generación a otra a lo largo de los años.

Para una de estas agrupaciones, lo transmitido se liga con lo maligno, enfatizando la existencia de un sello familiar cargado de elementos de maldad o error que no se repara, sino que sigue cobrando víctimas a lo largo de la historia familiar.

En el otro grupo, se incorpora el elemento de benignidad que, de no ser atendido, trasciende hacia lo maligno. Si bien se deja espacio para un posible tratamiento, aparece la angustia que implementa la negación de la muerte como defensa; más aun, cuando ellos estarían ubicándose como los transmisores de dicha dolencia.

Esto último adquiere mayor intensidad en los padres que poseen una mejor posición económica y que, por ello, cuentan con mayores probabilidades de poseer conocimientos acerca de la enfermedad y de acceder generalmente a los sistemas de salud, pensando por tanto en la opción de tratamiento.

Surgen, por otro lado, representaciones que depositan la génesis de la enfermedad en el vínculo que se establece entre la madre y el niño. El origen de la dolencia estaría determinada bien por problemas durante el proceso de gestación, bien por una alimentación y/o cuidados de la salud insuficientes o inadecuados, bien por carencias emocionales del niño o estados afectivos (rabia, depresión, angustia) de la madre que repercuten en su hijo. Todas ellas unidas forman un grupo representacional en el que se establece un nexo entre los posibles déficits en esta díada y el desarrollo de la neoplasia, pero se otorga también la posibilidad de curación con tratamiento, negando en todo momento el que bajo algunas circunstancias el pronóstico pudiera llevar a la muerte, pues esa opción implicaría que ellos, como padres, no podrían reparar sus errores.

En todas estas representaciones, los padres aluden fundamentalmente a lo que la madre ofrece - o priva - a su hijo, tanto a nivel físico 
como emocional, en las distintas etapas del desarrollo del niño. Se cuestiona así su calidad de nutriente, lo cual remite invariablemente a la evaluación de la relación temprana madre-niño.

En este sentido, el alimento como tal, al ser equiparable en términos simbólicos con el afecto, nos estaría hablando de un progenitor que siente que no es capaz de proveer lo suficiente o que ahoga a su hijo con sus cuidados.

Las ideas que ubican los orígenes del cáncer en los intentos de aborto durante el período de gestación presentes en algunos padres, pueden aludir a un embarazo no deseado con la consiguiente carga de agresión hacia el bebé; eso, al manifestarse la enfermedad, incrementaría los sentimientos de culpa.

Por otro lado, las representaciones que dan cuenta de la salud psicológica propia o la del hijo como fuentes de los procesos oncológicos hacen pensar en posibles conflictos emocionales previos al diagnóstico del niño que podrían dificultar el ajuste de los padres y del menor a la enfermedad.

La trascendencia de este aspecto emocional es resaltado por Montalbetti et al., (1996). Ellos señalan que no solo los síntomas físicos repercuten en el estado de ánimo del bebé enfermo, sino también en la relación madre-niño. Se observa cómo el tono de voz, los gestos, los latidos del corazón le trasmiten diversos sentimientos. Desde confianza y confort hasta terror, desconfianza, desesperanza, apatía y depresión. De acuerdo con el sentimiento de la madre, el niño se puede mostrar confiado y acogido o nervioso, irritable, sin deseos de jugar ni comer, o atender a los estímulos ambientales que antes podían motivarlo.

Winnicott (1957), por su parte, plantea que dado que la madre se constituye en una "mitad", una parte del bebé, debe incluso "poder enfermar" con él, es decir, sostener "el mal" o "lo malo" que siempre amenaza, tanto desde la realidad como desde el interior del nuevo ser. 
Representaciones aceca del cáncer y su origen en padre de niños diagnosticados...

Tomando en cuenta esto último, llama la atención la alta proporción en que son mencionadas las enfermedades anteriores como causas de las neoplasias, pues ello implicaría la evaluación del adecuado cumplimiento de las funciones correspondientes al rol paterno que tienen que ver con el cuidado que ofrecen al niño en términos corporales y que pueden traer consigo la inseguridad para afrontar la contención del menor en este momento en que se trata de una enfermedad más seria o riesgosa.

Otras representaciones relacionadas con la génesis del cáncer estarían dadas por aquellas que atribuyen el origen de las neoplasias malignas al consumo de sustancias, específicamente al uso de medicamentos, pues consideran que estas al mismo tiempo que curan pueden dañar otros órganos, particularmente cuando son empleadas sin haber sido prescritas por un doctor o cuando estas son recetadas en dosis muy altas.

Estas representaciones ponen en evidencia la ambivalencia y desconfianza que existe hacia los tratamientos médicos. Debe ponernos en alerta para evitar que el paciente o sus padres, en el caso de niños, abandonen la terapéutica que se les ofrece y opten, debido al temor de poder causar más daño a sus hijos, por otras que pueden ser inocuas para el caso de la enfermedad que se padece.

Ahora bien, hasta aquí hemos considerado estos resultados teniendo en cuenta que nuestra muestra esta constituida por padres de niños diagnosticados de cáncer; en este sentido, hemos dado particular peso a representaciones que aluden a la génesis del cáncer en los niños. No obstante, las representaciones dadas trascienden su situación actual y pueden ser trasladadas también a los pacientes adultos.

Mencionábamos, hasta hace un momento, a las representaciones en las que el uso de algunas sustancias, específicamente medicamentos, puede ser considerado un determinante en la génesis del cáncer. No obstante, no hemos abordado aún el peso que se adjudica al consumo 
de drogas (fundamentalmente cigarro, alcohol, té, café y otras drogas no legalizadas) en el desarrollo de procesos oncológicos. En estos casos, los hábitos que la persona adulta tenga determinarían su enfermedad, adjudicándole a ella toda la responsabilidad sobre su condición. Diremos en este sentido que está extendiéndose entre la población la información referida a los efectos dañinos del tabaco y otras drogas y la asociación de las mismas con el desarrollo de procesos cancerígenos.

A nivel de grupo representacional, el consumo de sustancias es el que aparece con mayor intensidad y dado que se prioriza la representación del cáncer como originado precisamente por el uso tanto de drogas como de medicamentos, no puede hablarse de una reacción de sorpresa o engaño, en tanto uno es responsable de su conducta. La enfermedad, en este caso, es considerada como incurable y por tanto mortal.

Posiblemente el centrar la atención sobre la enfermedad en personas mayores y no en los niños permite en alguna medida a los progenitores apartarse de su situación actual y por tanto hablar de la posibilidad de muerte de un modo más directo.

En el caso de aquellas representaciones que adjudican la causa del cáncer al tipo de vida sexual, nuevamente es el paciente el que aparece como responsable. Se trata de adultos vírgenes o con un ejercicio excesivo y promiscuo de su sexualidad. Se toma en cuenta también a mujeres multíparas y el uso algunos métodos anticonceptivos ( $T$ de cobre, espiral) que pueden ser perjudiciales para la salud.

Vemos, pues, que estas representaciones dejan traslucir las concepciones propias acerca de la sexualidad. Al respecto, llama especialmente la atención el que las conductas de tipo sexual están referidas a la mujer de manera casi exclusiva. Esto último lleva a pensar que subyace la idea de que el ejercicio de la sexualidad femenina puede enfermar, a diferencia de la del hombre, lo cual contiene significados especiales a nivel cultural. 
Representaciones aceca del cáncer y su origen en padre de niños diagnosticados...

Al mismo tiempo, se evidencian algunas distorsiones en términos de la información a la que se tiene acceso. Esto se hace particularmente patente y real cuando se habla del cáncer como una enfermedad que se contagia a través de la vía sexual. Ello supone, tal como lo mencionan León, Martínez y Gómez (1990) y Sontag (1996), un componente de voluntad en la adquisición de la enfermedad que la hace responsable y, por tanto, merecedora de un juicio más severo.

Estas últimas representaciones y aquellas que consideran que las neoplasias son adquiridas como resultado de una transfusión de sangre o cuando se entra en contacto con la sangre de un paciente, nos hacen tomar conciencia de la confusión existente entre el SIDA y el cáncer y de la necesidad de campañas educativas que aclaren este tema.

Respecto del contagio como encargado del desarrollo de las neoplasias, se mencionan, además, otros medios tales como el contacto directo con el enfermo o sus objetos personales. Estos constituyen algo así como mitos que también son compartidos con el SIDA. A ellos se refieren otros autores (León, Martínez y Gómez, 1990; Sontag, 1996), ligándolos a reacciones fóbicas o de pánico hacia la enfermedad en la población general. En términos de comportamiento se produciría un alejamiento del paciente que repercute de manera drástica en un posible aislamiento de la persona en un momento en que necesita especialmente del apoyo, cercanía y afecto de aquellos significativos en su vida.

No es casual entonces que surja un grupo representacional en el que lo sexual, como factor de adquisición de la enfermedad y el contagio, aparezcan relacionados. Se habla, entonces, de un animal que ataca y destruye el cuerpo y en que, para esos casos, la cura dependería fundamentalmente de la fe o la suerte.

El cáncer, en tanto enfermedad vinculada a desarreglos en la vida sexual, estaría cargada de infinidad de significados que, en muchas ocasiones, implicarían censura y crítica a la persona. La cura, 
por tanto, dependería del juicio y la bondad de Dios frente al comportamiento de uno.

Un último punto por discutir está referido a las diferencias que se encontraron en las representaciones que los padres y madres de un mismo niño tenían acerca del cáncer. Este es un dato de gran relevancia a pesar de que la muestra que nos conduce a este hallazgo es reducida. Ello nos hace pensar que el elemento personal, dado por la historia individual, las experiencias previas, los conocimientos anteriores y las fantasías propias, adquiere pues especial significación en las representaciones que uno se forma de las neoplasias malignas en contraste con el resto de variables (de la familia, del niño y de su enfermedad) que son tomadas en consideración y son comunes a ambos progenitores.

Aquí se evidencia en alguna medida que las representaciones, tal como lo propone Stern (1995), no se forman cuando lo externo se hace interno o se introyecta, sino que ellas se forman en el interior, tomando como base lo que a uno le pasa en relación con otros. La realidad externa se entrelaza, pues, progresivamente con el mundo imaginario cargado, entre otras cosas, de elementos subjetivos, representaciones mentales, fantasías, deseos, temores, sueños, memoria de su niñez que se ubican más allá del conocimiento articulado del mundo externo y que tiene más bien una fuente interna.

Ahora bien, si recordamos que las representaciones que los padres tienen sobre sus hijos y de ellos mismos, como padres, determinarán la naturaleza de la relación que se establece con los hijos (Stern, 1995) y a eso le agregamos que venimos trabajando con progenitores cuyos hijos acaban de ser diagnosticados con algún tipo de neoplasia maligna diremos que resulta de suma importancia conocer las representación que ellos tengan del cáncer como enfermedad y de su hijo como un niño que la padece, en tanto es probable que tenga un efecto en el afrontamiento que se tenga de esta situación y en el acercamiento al niño quien, a su vez, buscará representar su propia experiencia. 
Representaciones aceca del cáncer y su origen en padre de niños diagnosticados...

\section{Referencias}

Ajuriaguerra, J. y Marcelli, D. (1987) (2da. ed.). Manual de psicopatología del niño. Barcelona: Masson.

Banister, P., Burman, E, Parker, I., Taylor y Tindall, C. (1994). Qualitative methods in psychology. A research guide. Filadelfia: Open University Press.

Bion, W. R. (1967). Second thoughts. Londres: Karnac.

Bleger, L. (1964). El paciente y el cáncer. En L. Bleger (Ed.), Psicología y cáncer (75-93). Buenos Aires: Horme.

Calman, K. (1982). The care of advanced disease and psychological factors. En K. Halnan (Ed.), Treatment of cancer (pp.789-796). Nueva York: Igaku-Shoin.

Chavez-Ferrer, L. (1995). Soporte social en pacientes portadores del SIDA del Hospital Dos de Mayo de Lima. Tesis de licenciatura en psicología no publicada, Pontificia Universidad Católica del Perú, Lima.

Craig, G. (1992) (6ta. ed.). Desarrollo psicológico. México: University of Massachusetts.

Escuela Europea de Oncología (1997). Información sobre la conferencia consenso sobre psicooncología. Neoplasia, Oncología Multidisciplinaria, 14, 4, 44-45.

Farr, R. (1988). Las representaciones sociales. En S. Moscovici (Ed.), Psicología social (495-534). Barcelona: Paidós.

Feldman, D. (1974). Chronic disabling illness: a holistic view. Journal of chronic disease, 27, 287-291.

Freud, A. (1993). Normalidad y patología en la niñez. México: Paidós. Freud, S. (1915/1981). Consideraciones de actualidad sobre la guerra y la muerte. En L. López Ballesteros (Ed.), Obras completas (4ta. ed.). Barcelona: Biblioteca Nueva.

Freud, S. (1919/1981). Lo siniestro. En L. López Ballesteros (Ed.), Obras completas (4ta. ed.). Barcelona: Biblioteca Nueva.

Gala, F., Costa, C., Diaz, M. y Lupiani, M. (1994, ene-feb.). Cáncer frente a tumor: estudio de la carga ansiógena mediante diferencial semántico. Neoplasia, 11, 1, 18-22. 
Goldberg, D. (1981) Medicine as food. Exploring the unconscious meaning of cancer treatment. En J. Goldberg (Ed.), Psychotherapeutic treatment of cancer patient (182-203). Nueva York: The Free Press.

Hallford, G. (1993). Children's understanding. The development of mental models. Nueva York: Erlbaum.

Hernández, R., Fernández, C. y Baptista, P. (1991). Metodología de la investigación. Bogotá: Mc Graw Hill.

Hersh, S. (1979). Views on the psychosocial dimensions of cancer and cancer treatment. En A. Coelho (Ed.), Toward a new definition of health (pp. 175-190). Nueva York: Plenum Press.

Hersh, S. (1985). Psychological aspects of patients with cancer. En V. de Vita, S. Hellman y S. Rosenberg (Eds.), Cancer, principles and practice of oncology (pp. 247-278). Barcelona: Salvat.

Holland, J. C. (1982). Psychosocial aspects of cancer. En J. C. Holland y D. Frei (Eds.), Cancer medicine (pp. 1175-1203, 2325-2331). Filadelfia: Lea y Febiger.

Holland, J. y Cullen, L. (1986). Living with cancer. En A. Holleb (Ed.), The American Cancer Society Book. Prevention. Detection. Diagnosis. Treatment. Rehabilitation. Cure (pp. 3-14). Nueva York: Doubleday .

Instituto de Enfermedades Neoplásicas [INEN] (1994). Estadísticas internas. No publicado.

Jodelet, D. (1988). La representación social: Fenómenos, concepto y teoría. En S. Moscovici (Ed.), Psicología social (469-494). Barcelona: Paidós.

Johnson-Laird, P. N. (1985). Modelos mentales. En M. De Vega (Ed.), Introducción a la psicología cognitiva (469-499). Buenos Aires: Alianza Editorial.

Kerlinger, F. (1988). Investigación del comportamiento. México: Mc Graw Hill.

Klein, M. (1971). Psicoanálisis de niños. Obras completas. Buenos Aires: Paidós.

Koocher, G. (1980). Initial consultation with the pediatric cancer patient. En J. Goldberg (Ed.), Psychotherapeutic treatment of cancer patients (231-237). Nueva York: The Free Press. 
Representaciones aceca del cáncer y su origen en padre de niños diagnosticados...

Lakoff, G. (1987). Women, fire and dangerous things. What categories reveal about the mind. Chicago: The University of Chicago Press.

Laplanche, J. y Pontalis, J. B. (1993). Diccionario de psicoanálisis. Barcelona: Labor.

León, J. M., Martínez, M. y Gómez, T. (1990). Implicaciones psicosociales del SIDA y propuestas de intervención. En S. Barriga, J. M. León, M. F. Martínez y F. Jiménez (Eds.), Psicología de la salud: aportaciones desde la Psicología Social (pp. 375394). Sevilla: Librería Reguera.

Lockhart, R. (1981). Cancer in myth and dream. En J. Golberg (Ed.), Psychotherapeutic treatment of cancer patients. Nueva York: Free Press.

Lokich, J. (1978). Primer of cancer managment. Boston: McGraw Hill.

López Merino, Y. (1984). Manejo psiquiátrico en la práctica médica. Lima: Marte.

Loscertales, F. (1990). El niño enfermo y el personal de salud: implicaciones ante el fracaso escolar. En S. Barriga, J. M. León, M. F. Martínez y F. Jiménez (Eds.), Psicología de la salud: Aportaciones desde la psicología social (pp. 395-422). Sevilla: Librería Reguera.

Montalbetti, M. L., Ruda, L., Luy, G. y Cedrón, Y. (1996). Importancia del trabajo psicológico con infantes de 0-4 años en el Instituto de Enfermedades Neoplásicas. Ponencia presentada en el Simposio Primera infancia: El reto de una nueva vida, Lima.

Neimeyer, G. y Neimeyer, R. (1996). Definición de los límites de la evaluación constructivista. En G. Neimeyer (Ed.), Evaluación constructivista (11-19). Barcelona: Paidós Ibérica.

Nir, Y. y Maslin, B. (1980). Psychological adjustment of children with cancer. En J. Kellerman (Ed.), Psychological aspects of childhood cancer (263-272). Springfield, Illinois: Thomas Publisher.

Nouvillas, E. y Huici, C. (1990). Atribuciones sociales y cumplimiento terapéutico. En S. Barriga, J. M. León, M. F. Martínez 
y F. Jimenez (Eds.), Psicología de la salud: Aportaciones desde la psicología social (pp. 269-295). Sevilla: Librería Reguera.

Ovejero, A. (1990). Apoyo social y salud. En S. Barriga, J. M. León, M. F. Martínez y F. Jimenez (Eds.), Psicología de la salud: Aportaciones desde la psicología social (pp. 103-134). Sevilla: Librería Reguera.

Patton Quinn, M. (1990). Qualitative evaluation and research methods (2da. ed.). California: Sage.

Perrichi, C. (1986). El niño enfermo. Barcelona: Hercher.

Reátegui, N. (1990). Estructuras cognitivas y afectivas de madres y niños andinos. Ministerio de Planeamiento y coordinación UNICEF (Serie Estudios y Políticas para el Desarrollo de la Población Andina. Nro. 2). La Paz: ProAndes.

Rebolloso, E. (1990). Aspectos informativos de la relación médicopaciente: Conocimiento médico de la enfermedad en la población general y satisfacción con las informaciones recibidas por parte del personal sanitario. En S. Barriga, J. M. León, M. F. Martínez y F. Jimenez (Eds.), Psicología de la salud: Aportaciones desde la psicología social (pp. 221-267). Sevilla: Librería Reguera.

Renneker, R. (1980). Cancer and psychotherapy. En J. Golberg (Ed.), Psychotherapeutic treatment of cancer patients (131-166) . Nueva York: The Free Press Editorial.

Rodríguez, J., López, C. y Pastor, M. A. (1990). Estrategias de afrontamiento de la enfermedad. En S. Barriga, J. M. León, M. F. Martínez y F. Jimenez (Eds.), Psicología de la salud: Aportaciones desde la psicología social (pp.159-195). Sevilla: Librería Reguera.

Ruda, L. (1998). Representaciones acerca del cáncer y su origen en padres de niños diagnosticados con esta enfermedad. Tesis para optar el grado de licenciada en Psicología, Pontificia Universidad Católica del Perú.

Schavelzon, J. (1978). El paciente, el médico y la familia. Trabajo presentado en el Simposio 21 del XII Congreso Internacional del Cáncer El impacto psicológico del cáncer, Madrid. 
Representaciones aceca del cáncer y su origen en padre de niños diagnosticados...

Schmale, A. (1978). Principios de oncología psicosocial. En Sociedad Americana del Cáncer, Oncología clínica: Para estudiantes de medicina y médicos. Un enfoque terapéutico multidisciplinario (5ta. ed.). Nueva York: Universidad de Rochester.

Sherman, C. D. (1992). Aspectos psicosociales del cáncer. En J. Estapé (Ed.), Manual de oncología clínica (5ta. ed.) (170-177). Barcelona: Domma.

Shilder, P. (1977). Imagen y apariencia del cuerpo humano. Buenos Aires: Paidós.

Solidoro, A. (1983). Tratamiento médico del cáncer. Liga Peruana de Lucha contra el Cáncer. Lima: Talleres Gráficos.

Sontag, S. (1996). La enfermedad y sus metáforas. Madrid: Santillana, Taurus.

Spitz, R. (1986). El primer año de vida (3ra. ed.). Madrid: Aguilar.

Stern, D. (1995). The motherhood constellation. A unified view of parentinfant psychotherapy. Nueva York: Basic Books - Harper Collins .

Valls, J. L. (1995). Diccionario freudiano. Buenos Aires: Julian Yebenes.

Winnicott, D. (1957). Mother and child: A primer of first relationship. Nueva York: Basic Books.

Winnicott, D. (1965). The madurational process and the facilitating environment. Nueva York: International Universities Press. 